\title{
Effect of canal width contraction on the hydraulic parameters and scour downstream water structures
}

\author{
Mohamed A. Ashour, Tawab E. Aly, Mahmoud M. Mostafa \\ Department of Civil Engineering, Faculty of Engineering, Assiut University, 71515 Assiut, Egypt, e-mail: mashour475275@yahoo.com; \\ tawab_aly@yahoo.com (*corresponding author); eng.mmm91@yahoo.com
}

\begin{abstract}
The dimensions of many water streams, which satisfy proper hydraulic conditions, may not be compatible with the designed dimensions of an irrigation work that needs to be constructed in some locations. The design requirements of such irrigation works may involve a contraction in the channel width in the required location. This contraction, of course, affects different flow properties and the scour hole formed downstream of these structures. Therefore, the present experimental study aims to investigate the effect of the transition angle and the contraction on the flow properties and on the scour phenomenon downstream water structures. Through 460 experimental runs, carried out on 20 experimental models, the study proved that, for an efficient hydraulic performance and economic design, the best transition angle $(\theta)$ for the approaches of water structures is $30^{\circ}$ with a relative contracted width ratio $(r=b / B)$ not less than 0.6 .
\end{abstract}

Key words: relative contracted width ratio, transition angle, specific energy, hydraulic parameters, scour

\section{Introduction}

Some changes in water stream dimensions may be necessary in some construction locations to ensure the perfect hydraulic performance of the water structure with minimum costs. One of the most frequent changes is the reduction of the original water stream bed width. The present research focuses on investigating this reduction from three points of view: $(i)$ the optimum relative contracted width ratio $(r=b / B)$; (ii) the most suitable transition angle before and after the contracted reach; (iii) the effect on scour phenomenon downstream of the structure.

The contraction of water streams has encouraged many researchers to introduce equations for estimating its properties and limitation experimentally and theoretically. Ippen and Dawson (1951) found that a straight contraction is better than a curved one of equal length in hydraulic performance and cost. Henderson (1966) stated that the limiting contraction ratio may be calculated by using an energy balance between the upstream and the critical contraction sections, or by using a momentum balance between the critical contraction and downstream sections; he derived equations for the two cases which are reviewed and modified by Zidan et al. (1990). Wu and Molinas (2005) also devised a theoretical equation to predict the limiting contraction from the conservation of energy and continuity principles. Negm et al. (2003) and Attia and Alhomidan (2013) investigated the protection length downstream of a sudden transition for subcritical flow. They found that the relative protection length increases with the decrease of the relative contracted width ratio. Zidan et al. (2015) studied compound transitions in open channels and they concluded that the values of the energy and momentum coefficients depend on the discharge, relative contracted width ratio, and size of the hump.

The angle of transition has also been studied by many authors. Alsamman (1989) investigated the effect of transition angle and concluded that the coefficient of contraction decreases with increasing the transition inlet angle from $30^{\circ}$ to $90^{\circ}$, while the transition outlet angle has an insignificant effect on the coefficient of contraction. Moreover, the relative transition length, $(L / b)$, has no remarkable effect on the contraction coefficient when $(L / b)$ is greater than five. Attia (2000) investigated the effect of the inlet angle of transition; he found that the inlet angle has a pronounced effect on energy loss up to an angle of about $30^{\circ}$, with a slight effect in the range from $30^{\circ}$ to $45^{\circ}$ and a minor effect at greater angles.

The scour is one of the main factors affected by the canal width contraction. Day and Raikar (2005) studied scour in long contractions. It was found that scour depth increases with increasing the sediment size for gravel 
and with a decrease in the contract width of the channel. It decreases with increasing the Froude number for larger ratios of relative contracted width. Devadson (2007) noted that the depth of flow and the geometry of the contraction section significantly affected the final scour depth in cohesive soils with deeper flows and harsh contractions resulting in increasing scour depths. Xiong et al. (2013) concluded that contraction length had only a slight effect on the maximum scour depth and equilibrium bed morphologies. Mohamed et al. (2016) investigated the effect of different relative contracted width ratios on local scour depth, where $90 \%$ of the maximum scour depth was achieved in two hours. From a technical survey of the previous research concerning canal width contraction it was concluded that canal width contraction significantly affects the different hydraulic parameters and both scour depth and length. However, studying the effect of relative contracted width ratios, transition angle before and after the contracted section, and the scour depth and length is too wide a task for only one investigation; further research is necessary, from which the importance of the present study comes.

\section{Methods}

\section{Theoretical approach}

A schematic diagram for the experimental model of the present research and all parameters affected by the contraction of the canal are presented at Figure 1. The different affecting parameters can be summarized as follows:
- $B$ - original channel width,

- $b$ - contracted channel width,

- $D_{50}$ - mean particle diameter,

- $D_{\text {se }}$ - equilibrium scour depth,

- $\Delta E_{1}$ - upstream energy loss,

- $g$-gravitational acceleration,

- $h_{u}$ - heading up,

- $L^{u}$ - transition length,

- Lse - equilibrium scour length,

- Q - discharge,

- $r$ - relative contracted width ratio $(b / B)$,

- $S$ - bed slope,

- $v_{1}$ - water velocity,

- $y_{1}$ - upstream water depth,

- $y_{2}$ - downstream water depth,

- $y_{\mathrm{s}}-$ water depth through contraction,

- $\theta$ - transition angle,

- $\mu$-dynamic viscosity of water,

- $\rho$ - water density,

- $\rho_{S}-$ density of the sand layer,

- $\sigma$-surface tension.

The general relation for the effect of variables on hydraulic parameters may be written as:

$$
f\left(\rho, v_{1,} y_{1}, y_{S}, y_{2}, h_{u}, \Delta E_{1}, L, B, b, \mu, \sigma, g, Q, \theta, S\right)=0 .[1]
$$

By using Buckingham's $\pi$ theorem with three repeating variables $\rho$, $v_{1}$ and $y_{1}$, the equation (1) can be written as follows:

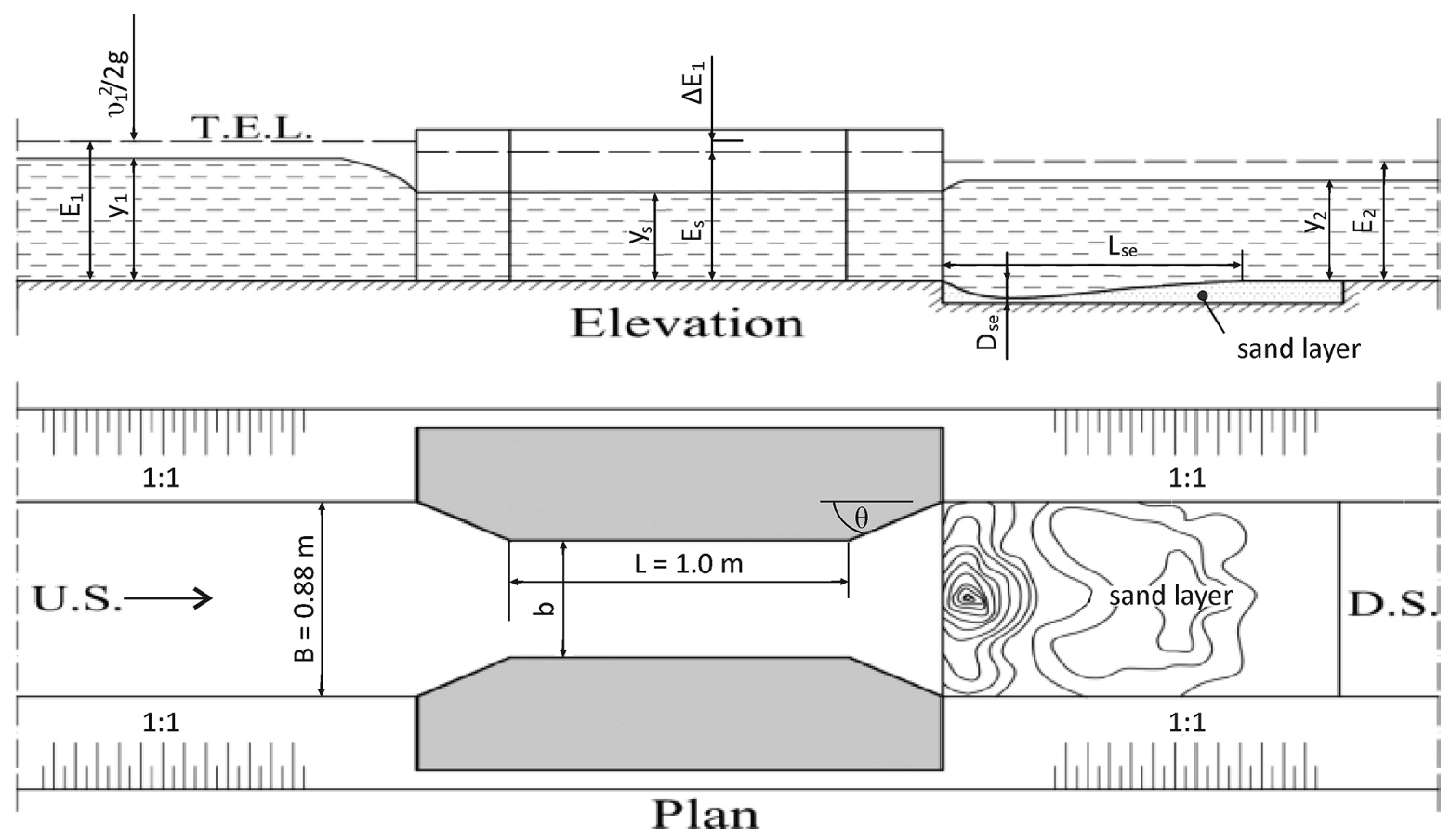

Fig. 1. Definition sketch of the experimental model 


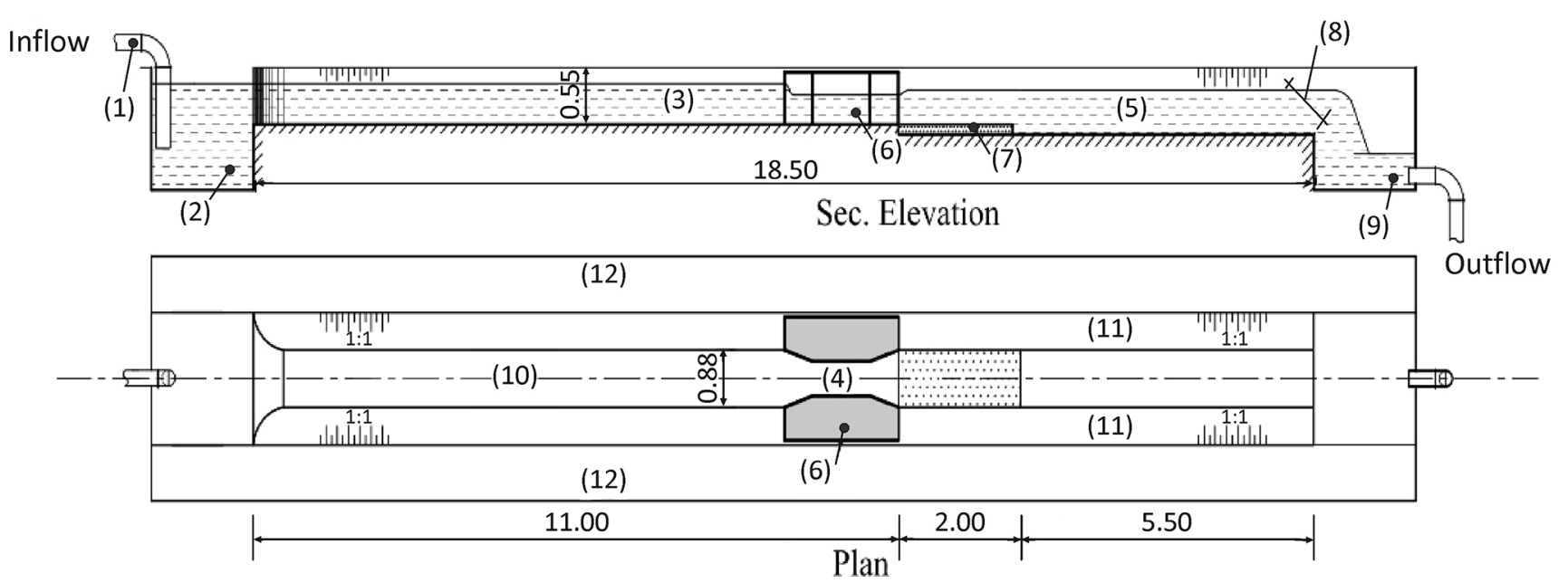

Fig. 2. Schematic diagram of the experimental facility.

Explanation: (1) - feeding pipe line, (2) -inlet tank, (3) - upstream section, (4) - contraction section, (5) - downstream section, (6) - contracted model, (7) - sand layer, (8) - tail gate, (9) - outlet tank, (10) - channel bed, (11) - channel side slope, (12) - channel foot path.

$$
\begin{gathered}
f\left(y_{S} / y_{1}, y_{2} / y_{1,}, h_{u} / y_{1}, \Delta E_{1} / y_{1}, L / y_{1}, B / y_{1}, b / y_{1}, \mu /\left(\rho \cdot v_{1} \cdot y_{1}\right),\right. \\
\left.\left(\rho \cdot v_{1}^{2} \cdot y_{1}\right) / \sigma, v_{1} /\left(g \cdot y_{1}\right)^{0.5}, Q /\left(g \cdot y_{1}^{5}\right)^{0.5}, \theta, S\right)=0 .
\end{gathered}
$$

where: $\rho \cdot v_{1} \cdot y_{1} / \mu=\operatorname{Re}$ (Reynolds number), $v_{1} /\left(g \cdot y_{1}\right)^{0.5}=F_{1}$ (Froude number at upstream section), $Q /\left(g \cdot y_{1}^{5}\right)^{0.5}=Q^{*}$ (discharge factor), $\rho \cdot v_{1}^{2} \cdot y_{1} / \sigma=W e$ (Weber number), and $\left(b / y_{1}\right) /\left(B / y_{1}\right)=b / B=r$ (relative contracted width ratio). Then the equation (2) can be written in the following form:

$f\left(y_{S} / y_{1}, y_{2} / y_{1,} h_{u} / y_{1}, \Delta E_{1} / y_{1}, L / y_{1}, r, R e, W e, F_{1}, Q^{*}, \theta, S\right)=0$. [3]

The effect of $(R e)$ and (We) can be neglected, the channel bed slope $(S)$ is constant and approximately equals zero, and the transition length $(L)$ is constant. So, the general equation could be reduced to:

$$
f\left(y_{S} / y_{1}, y_{2} / y_{1}, h_{u} / y_{1}, \Delta E_{1} / y_{1}, r, F_{1}, Q^{*}, \theta\right)=0 .
$$

The general relation for the effect of variables on the scour phenomenon may be written as in equation (5):

$$
f\left(\rho, v_{2}, y_{2}, D_{s e^{\prime}} L_{s e^{\prime}} L, B, b, g, \rho_{S^{\prime}}, D_{50^{\prime}} \theta\right)=0 .
$$

To estimate the effect of canal width contraction on the scour depth and length, and by using Buckingham's $\pi$ theorem with $\rho, v_{2}$ and $y_{2}$ as repeating variables, the equation (5) can be represented in the following form:

$f\left(L_{s e} / y_{2}, D_{s e} / y_{2} L / y_{2}, B / y_{2}, b / y_{2}, v_{2} /\left(g \cdot y_{2}\right)^{0.5}, \rho_{S} / \rho, D_{50} / y_{2}, \theta\right)=0$. [6]

The effect of the density ratio $\left(\rho_{s} / \rho\right)$ and the main diameter of the used sand $\left(D_{50}\right)$ are excluded, because only one fluid and one soil are used during the experiments, also the transition length $(L)$ is constant, $\left(b / y_{2}\right) /$
$\left(B / y_{2}\right)=b / B=r($ relative contracted width ratio $)$ and $v_{2} /\left(g \cdot y_{2}\right)^{0.5}=F_{2}$ (Froude number at downstream section). Then equation (6) could be reduced to:

$$
f\left(L_{s e} / y_{2}, D_{s e} / y_{2}, r, F_{2}, \theta\right)=0 .
$$

\section{Experimental set-up}

Experiments were carried out in the Irrigation and Hydraulic Laboratory of the Civil Engineering Department, Faculty of Engineering, Assiut University, Egypt, using a horizontal channel of trapezoidal cross-section of $18.5 \mathrm{~m}$ length, $0.88 \mathrm{~m}$ bottom width, $0.55 \mathrm{~m}$ depth and side slope 1:1. The water was supplied from the laboratory closed system with a constant head. Figure 2 shows a schematic diagram of the experimental facility.

\section{Experimental approach}

All models in the study were made of Perspex as shown in Figure 3, the research started with pre-experimental tests for estimating the needed time $(T)$ for establishing the maximum scour depth. The model used in these tests had a relative contracted width ratio $(r)$ $=0.6$ and the transition angle $(\theta)$ in the upstream and downstream sections equals $90^{\circ}$. The value of downstream water depth $\left(y_{2}\right)$ used for studying the scour during the research was taken as $20 \mathrm{~cm}$. Three available discharges were used, representing the minimum, maximum available discharges and an in-between value $\left(13.6,30.9\right.$ and $25.8 \mathrm{dm}^{3} \mathrm{~s}^{-1}$ respectively). For each discharge, seven runs were carried out by changing the time to 15 and 30 minutes, 1, 2, 4, 6, and 10 hours. The topography of the sand layer was measured by using an electrical point gauge at each $10 \mathrm{~cm}$ in the direction of the flow and the lateral direction. The contour map was 


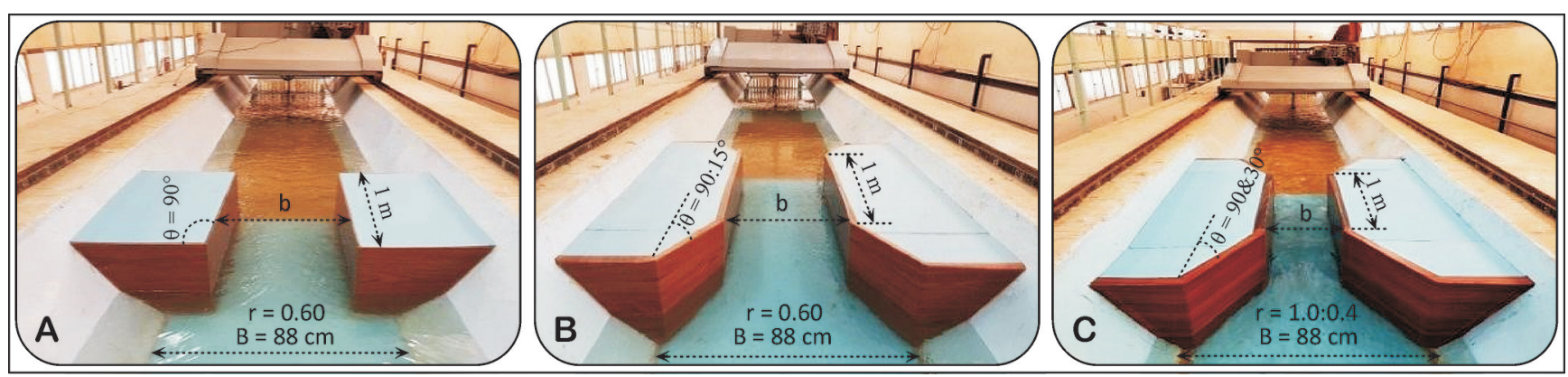

Fig. 3. Photos of the experimental models

A - Estimating the time $(T)$ for maximum scour, B - Studying the effect of the transition angle $(\theta), C$ - Investigating the effect of the relative contracted width ratio $(r)$.

plotted using the surfer program and the maximum scour depth and length were determined. After finishing these pre-experimental tests through 21 experimental runs, the two main stages of the experimental program were carried out, the first for studying the effect of the transition angle $(\theta)$ which included 36 experimental runs, and the second for studying the effects of the relative contracted width ratio $(r)$ which included 403 experimental runs.

For studying the effect of the transition angle $(\theta)$ on the different hydraulic parameters and scour, six models were used having a transition angle equalling 90 , $60,45,30,20$, and $15^{\circ}$ (stage 1 ). For each transition angle, five downstream water depths were used $\left(\mathrm{y}_{2}=10\right.$, $15,20,25$ and $30 \mathrm{~cm})$. The scour depth and length were measured only at a downstream water depth $\left(\mathrm{y}_{2}\right)=20$ $\mathrm{cm}$. The used discharge was $25.8 \mathrm{dm}^{3} \mathrm{~s}^{-1}$. All models in this stage had the same relative contracted width ratio $(r)=0.6$. The time of measuring the maximum scour depth $(T)$ was taken as concluded in the pre-experimental tests.

The main object of the present study is centred on stage 2 , which investigates the effect of the relative contracted width ratio $(r)$ on the different hydraulic parameters and scour downstream water structures. So, in this stage, six values of discharge were used, varying between 13.6 and $30.9 \mathrm{dm}^{3} \mathrm{~s}^{-1}$ with each model to introduce accurate formulae. In this stage, the transition angle $(\theta)$ in the upstream and downstream sections was taken as the efficient one concluded in stage 1 , in addition to $\theta=90^{\circ}$ as a reference for comparison purposes. For each transition angle, six values of the relative contracted width ratio were used $(0.4,0.5,0.6,0.7,0.8$, and $0.9)$ in addition to the case of no contraction $(r=1)$. Thus, 13 models were performed in this stage. For each relative contracted width ratio, five available downstream water depths were used $(10,15,20,25$ and 30 $\mathrm{cm})$. The scour depth and length were measured only at a downstream water depth $y_{2}=20 \mathrm{~cm}$ and discharge $Q$ $=25.8 \mathrm{dm}^{3} \mathrm{~s}^{-1}$ as they were used in the pre-experimental tests.

\section{Results and discussion}

\section{Pre-experimental tests}

The pre-experimental tests aimed to determine the time at which the scour depth reaches the equilibrium state. Figure 4 shows the relation between the scour depth ratio $\left(D_{s} / D_{s e}\right)$ and the time $(T)$, for the used discharges. From the figure it can be seen that, for the used sand $\left(D_{50}=0.42 \mathrm{~mm}\right)$ the scour depth increases with the increase of the discharge and time, as the rate of scour is very high at the beginning of the test reaching about $90 \%$ in the first 30 minutes. Also, the scour depth reaches its equilibrium state after about six hours for all used discharges. So, the time of measuring the maximum scour depth was chosen as six hours for the following stages.

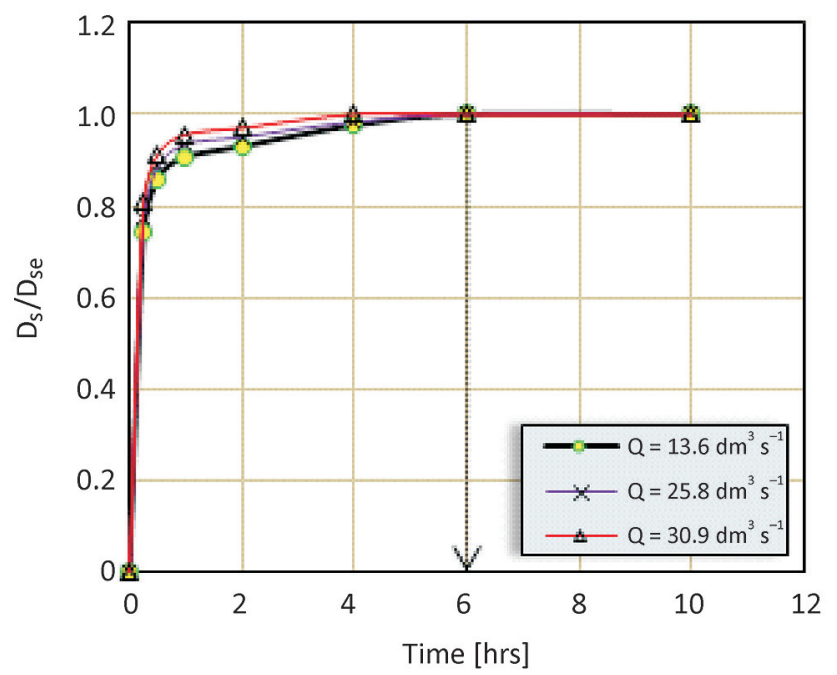

Fig. 4. Relation between the scour depth ratio $\left(D_{s} / D_{s e}\right)$ and the time $(T)$, for the used discharges

\section{Determining the effect of the transition angle on the different hydraulic parameters}

At this stage, we aimed to investigate the effect of the transition angle $(\theta)$ on the different hydraulic parameters such as water depth, Froude number, energy 


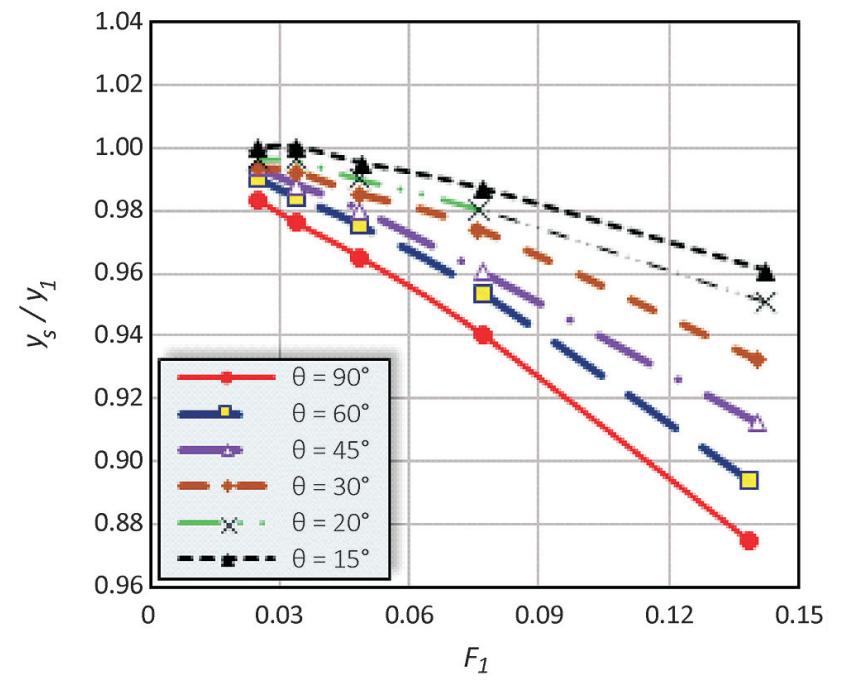

Fig. 5. Relation between the relative water depth at contraction $\left(y_{s}\right)$ $\left.y_{1}\right)$ and the upstream Froude number $\left(F_{1}\right)$

loss and scour depth and length downstream of water structures to determine the optimum transition angle from the hydraulic point of view and according to the cost of the wing wall. Figure 5 shows the relation between the relative water depth at contracted section $\left(y_{s} / y_{1}\right)$ and the upstream Froude number $\left(F_{1}\right)$, for the used transition angles at discharge $(Q)=13.6 \mathrm{dm}^{3} \mathrm{~s}^{-1}$. The figure clearly shows that the relative water depth decreases with increasing the upstream Froude number, and at any value of the upstream Froude number, the relative water depth decreases with increasing the transition angle. As the flow is subcritical, increasing the upstream Froude number causes a decrease in the water depth at the contracted zone and increases the upstream water level. The transition length between the

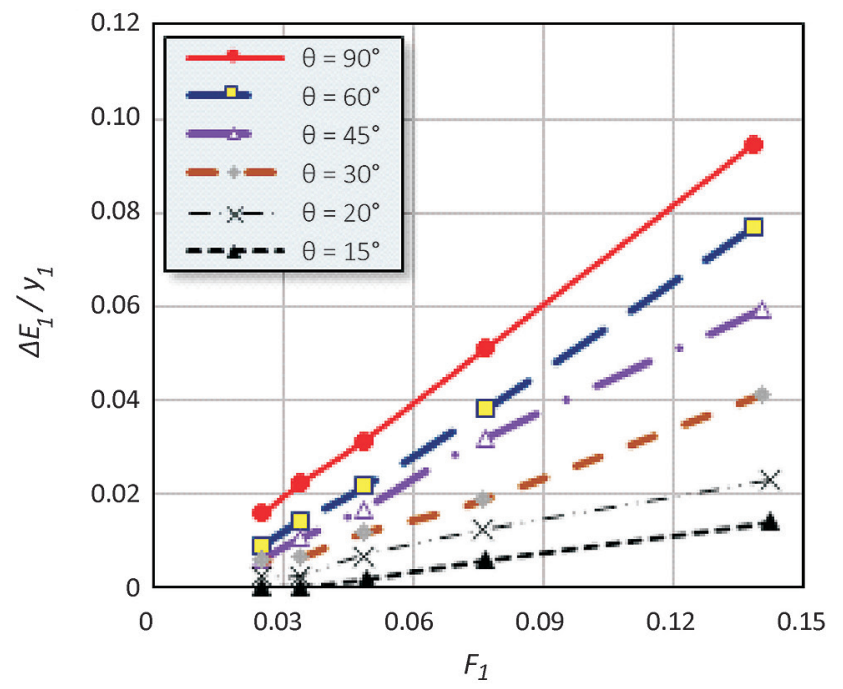

Fig. 6. Relation between the relative upstream energy loss $\left(\Delta \mathrm{E}_{1} / y_{1}\right)$ and the upstream Froude number $\left(F_{1}\right)$

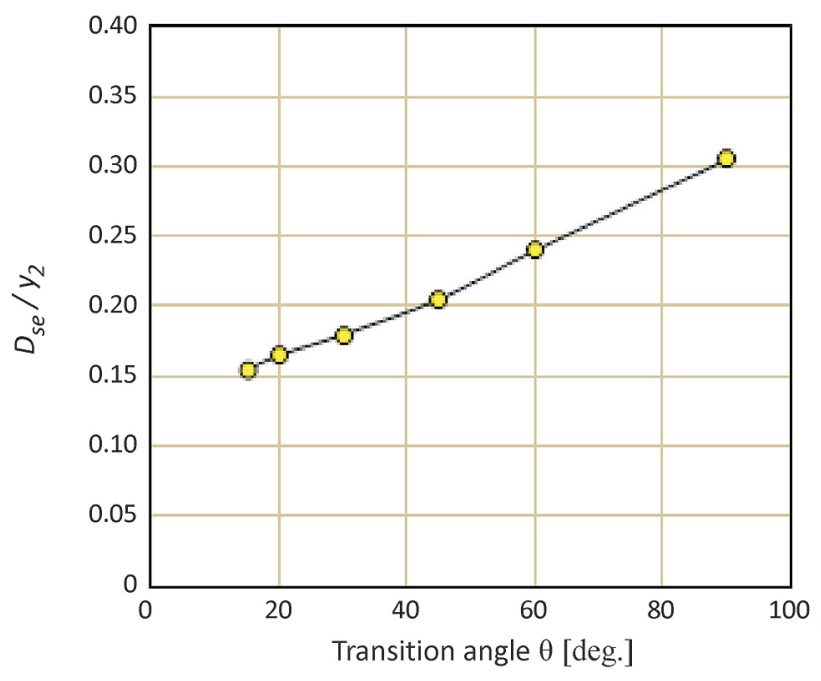

Fig. 7. Relation between the relative scour depth $\left(D_{s e} / y_{2}\right)$ and the transition angle $(\theta)$, at $r=0.6$

original width and the contracted width decreases with the increase of the transition angle, so at small transition angles, the flow changes gradually with low values and at large transition angles, the flow changes at a small distance with high values.

Figure 6 shows the relation between the relative upstream energy loss $\left(\Delta \mathrm{E}_{1} / y_{1}\right)$ and the upstream Froude number $\left(F_{1}\right)$, for all transition angles at discharge $(Q)$ $=13.6 \mathrm{dm}^{3} \mathrm{~s}^{-1}$, from which it is obvious that the relative upstream energy loss increases by increasing the upstream Froude number, and at any value of the upstream Froude number, the relative upstream energy loss increases by increasing the transition angle.

Figure 7 shows the relation between the relative scour depth $\left(D_{s e} / y_{2}\right)$ and the transition angle $(\theta)$, for relative contracted width ratio $(r)=0.6$, at discharge $(Q)$ $=25.8 \mathrm{dm}^{3} \mathrm{~s}^{-1}$, from which it can be concluded that the relative scour depth increases by increasing the transition angle where using transition angles $60,45,30,20$, and $15^{\circ}$ decreases the scour depth by about $21,33,41$, 46 , and $49 \%$ respectively compared with the $90^{\circ}$ transition angle. Because the distance between the contracted zone and the sand layer (the transition length) increases by decreasing the transition angle which allows the flow to return gradually to its origin without a sudden change or disturbance in the water surface, there is a decrease in the scour with the decrease of transition angle.

Fig. 8 shows the relation between the relative scour length $\left(L_{s e} / y_{2}\right)$ and the transition angle $(\theta)$, for a relative contracted width ratio $(r)=0.6$, at discharge $(Q)=25.8$ $\mathrm{dm}^{3} \mathrm{~s}^{-1}$. The figure shows that the relative scour length increases by increasing the transition angle where using transition angles $60,45,30,20$, and $15^{\circ}$ decreases the scour length by about $26,35,43,47$, and $49 \%$ respectively compared with the $90^{\circ}$ transition angle. 


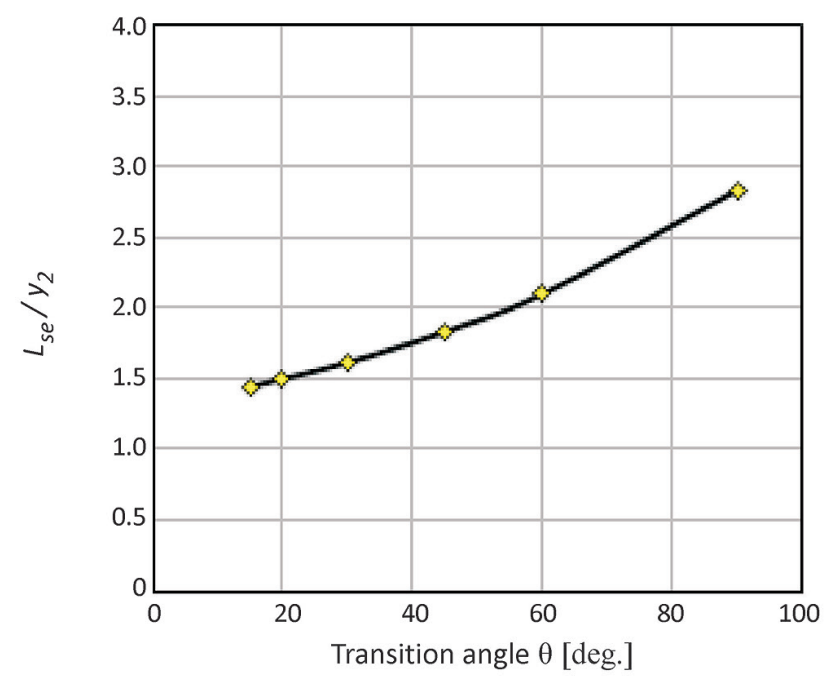

Fig. 8. Relation between the relative scour length $\left(L_{s e} / y_{2}\right)$ and the transition angle $(\theta)$, at $r=0.6$

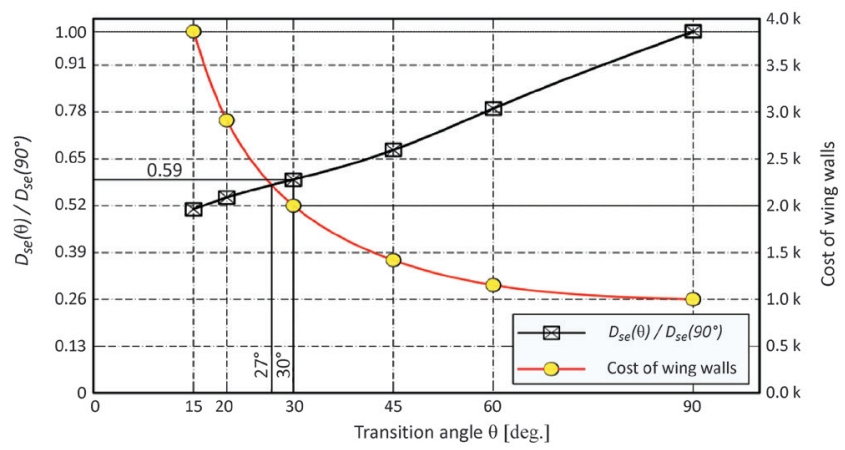

Fig. 9. Relation between the relative scour depth $\left(D_{s e}(\theta) / D_{s e}\left(90^{\circ}\right)\right)$, the cost of the wing wall, and the Transition angle $(\theta)$

In order to determine the optimum transition angle $(\theta)$ from the hydraulic point of view and according to

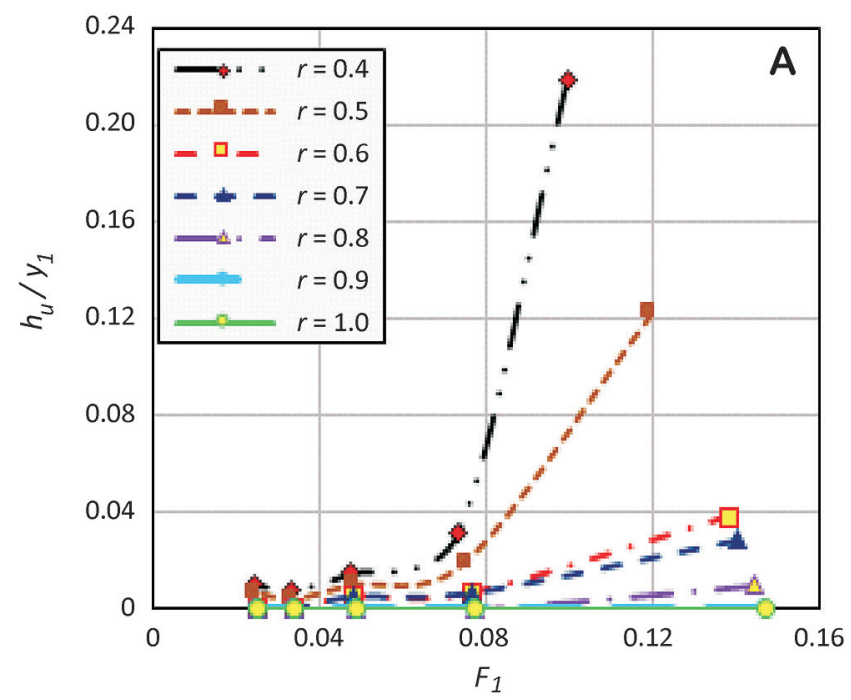

the cost of the wing wall, the relation between the relative scour depth, the cost of the wing wall, which can be considered as a function of its length, and the transition angle, was plotted as shown in Figure 9, which indicates that the two curves intersect at a transition angle $\theta=27^{\circ}$ approximately. So, for the practical design, the optimum transition angle was chosen to be equal to $30^{\circ}$ for the next stage. Although an angle of $90^{\circ}$ renders the minimum cost of wing walls, it provides the maximum depth and the maximum length of scour which increases the cost of the structure by increasing the protection length downstream. While using approaches with a transition angle of $30^{\circ}$ increases the cost of wing walls twofold it decreases the scour depth and length by about $42 \%$ compared with an angle of $90^{\circ}$, which both hydraulically and economically is much more effective. The effect of the transition angle represents a significant cost regarding the overall cost of the hydraulic structure depending on the dimension of the waterway, where for small waterways the cost of wing walls upstream and downstream of the structure may be equal or higher, in some cases, than the cost of the hydraulic structure itself. This impact decreases with the increase of the width of the waterway thus increasing the dimensions and cost of hydraulic structure.

The symbol " $k$ " in the figure is a constant and represents the cost of wing walls in the case of $\theta=90^{\circ}$ which increases with the increase in the length of wing walls for angles less than $90^{\circ}$.

\section{Investigating the effect of the relative contracted width ratio on the different hydraulic parameters}

At this stage, we aimed to investigate the effect of the canal width contraction on the different hydraulic parameters such as water depth, Froude number, energy loss and scour depth and length downstream

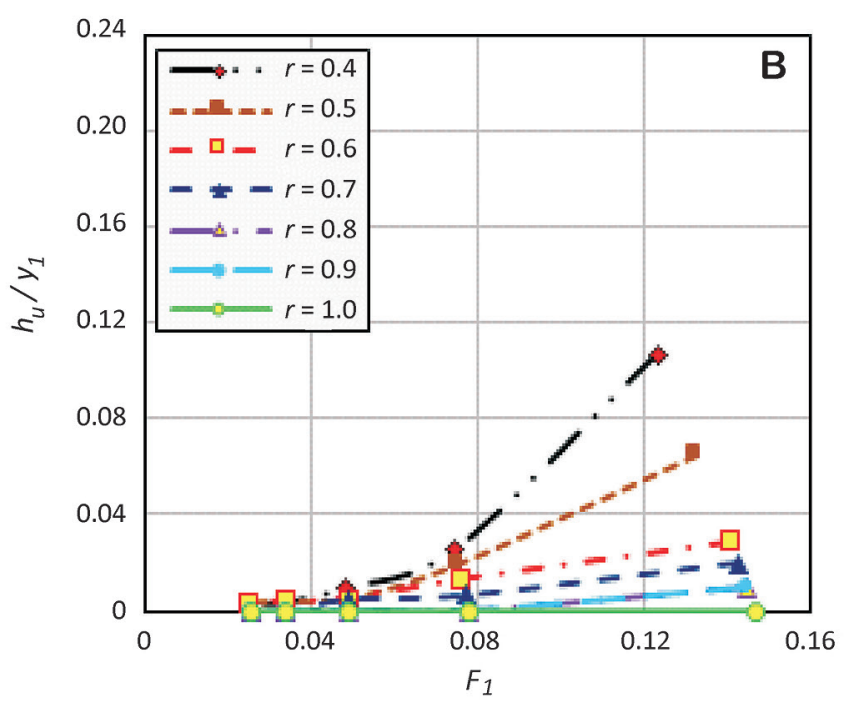

Fig. 10. Relation between the relative heading up $\left(h_{u} / y_{1}\right)$ and the Froude number $\left(F_{1}\right)$, at $\theta=90^{\circ}(\mathrm{A})$ and $\theta=30^{\circ}(\mathrm{B})$ 

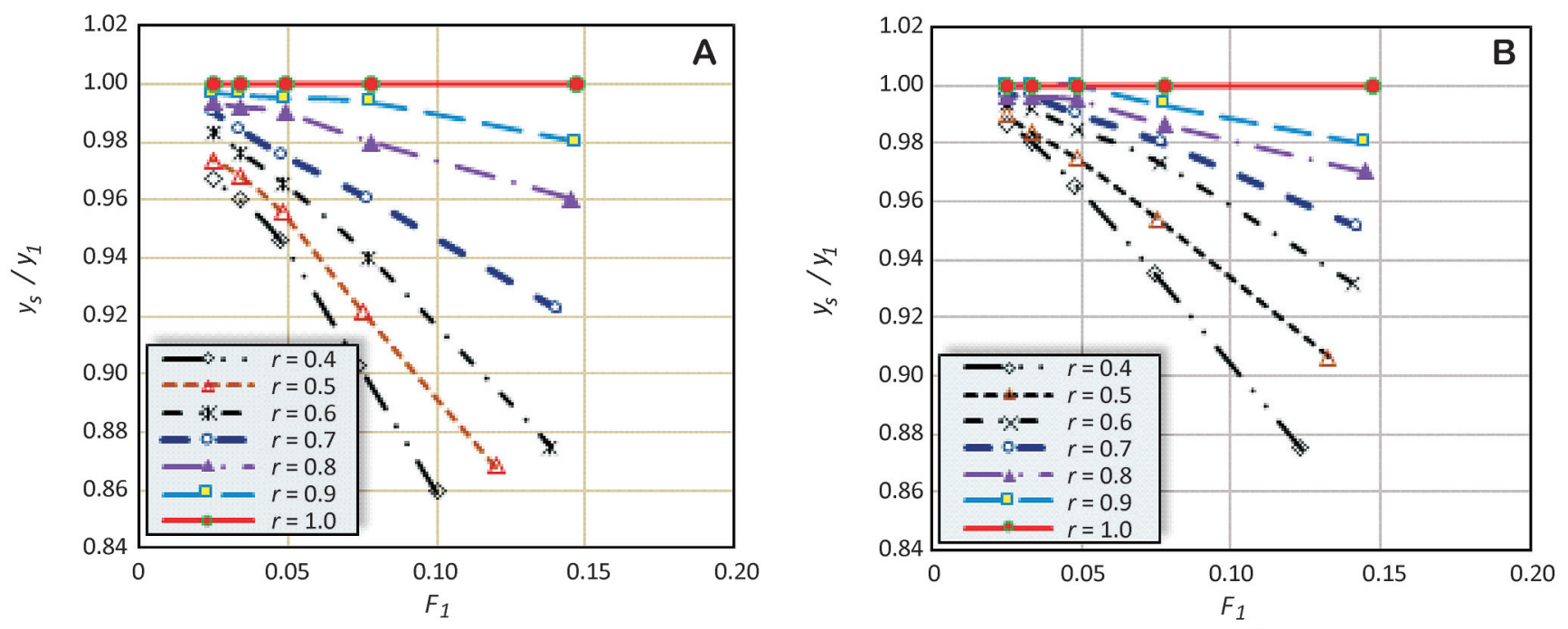

Fig. 11. Relation between the relative water depth $\left(y_{s} / y_{1}\right)$ and the upstream Froude number $\left(F_{1}\right)$, at $\theta=90^{\circ}(\mathrm{A})$ and $\theta=30^{\circ}(\mathrm{B})$

of the irrigation structures. To determine the effect of the relative contracted width ratio on the heading up, Figure 10 was plotted to show the relation between the relative heading up $\left(h_{\nu} / y_{1}\right)$ and the upstream Froude number $\left(F_{1}\right)$, for the used relative contracted width ratios at $\theta=90^{\circ}$ and $30^{\circ}$ for discharge $Q=13.6 \mathrm{dm}^{3}$ $\mathrm{s}^{-1}$. The graphs show that the relative heading up increases by increasing the upstream Froude number, and at any value of the upstream Froude number, the relative heading up increases by decreasing the relative contracted width ratio. And the main conclusion is that, the rate of increasing the heading up is very high at relative contracted width ratios less than 0.6 for the two used transition angles. Accordingly, the better recommended relative contracted width ratio should not be less than 0.6 .

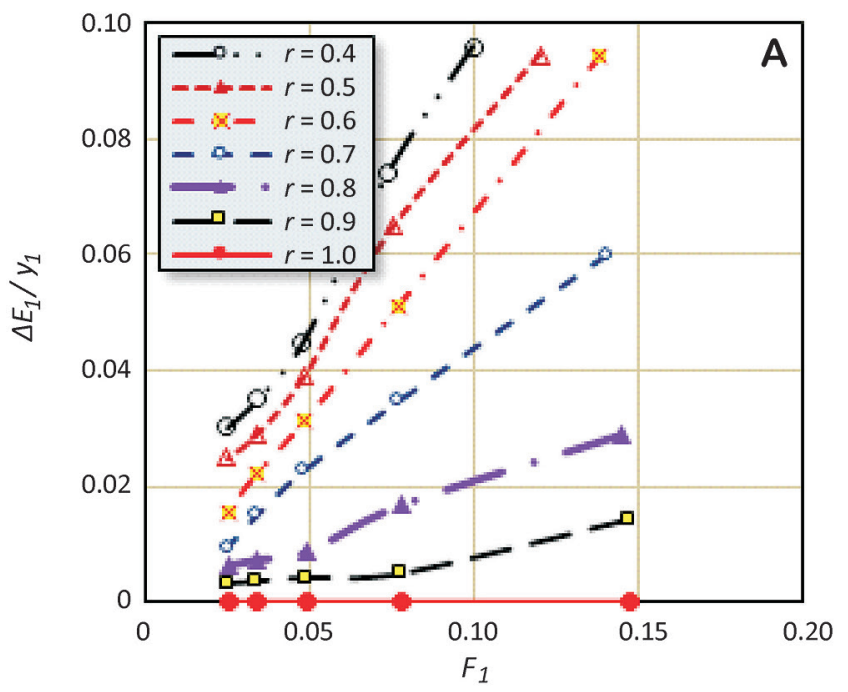

To determine the effect of the relative contracted width ratio on the water depth, Figure 11 was plotted to show the relation between the relative water depth at the contracted section $\left(y_{s} / y_{1}\right)$ and the upstream Froude number $\left(F_{1}\right)$, for discharge $Q=13.6 \mathrm{dm}^{3} \mathrm{~s}^{-1}$. From which it is clear thatthe relative upstream water depth decreases with increasing the upstream Froude number, and at a constant upstream Froude number, the relative upstream water depth decreases with decreasing the relative contracted width ratio.

To determine the effect of the relative contracted width ratio on energy loss, Figure 12 was plotted to show the relation between the relative upstream energy loss $\left(\Delta \mathrm{E}_{1} / y_{1}\right)$ and the upstream Froude number $\left(F_{1}\right)$, for discharge $Q=13.6 \mathrm{dm}^{3} \mathrm{~s}^{-1}$. The graphs clearly indicate that the relative upstream energy loss increases by in-

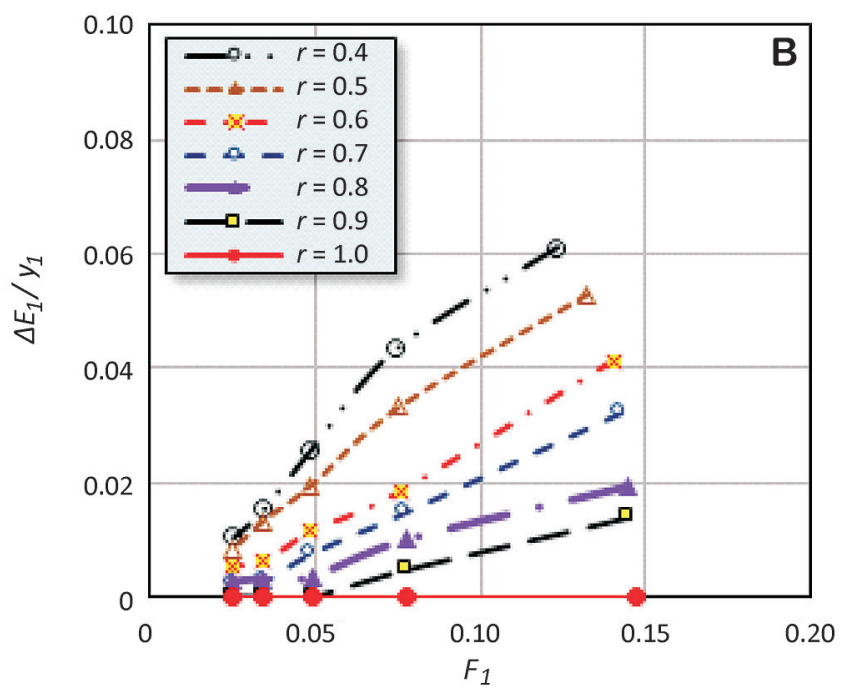

Fig. 12. Relation between the relative upstream energy loss $\left(\Delta \mathrm{E}_{1} / y_{1}\right)$ and the upstream Froude number $\left(F_{1}\right)$, at $\theta=90^{\circ}(\mathrm{A})$ and $\theta=30^{\circ}(\mathrm{B})$ 


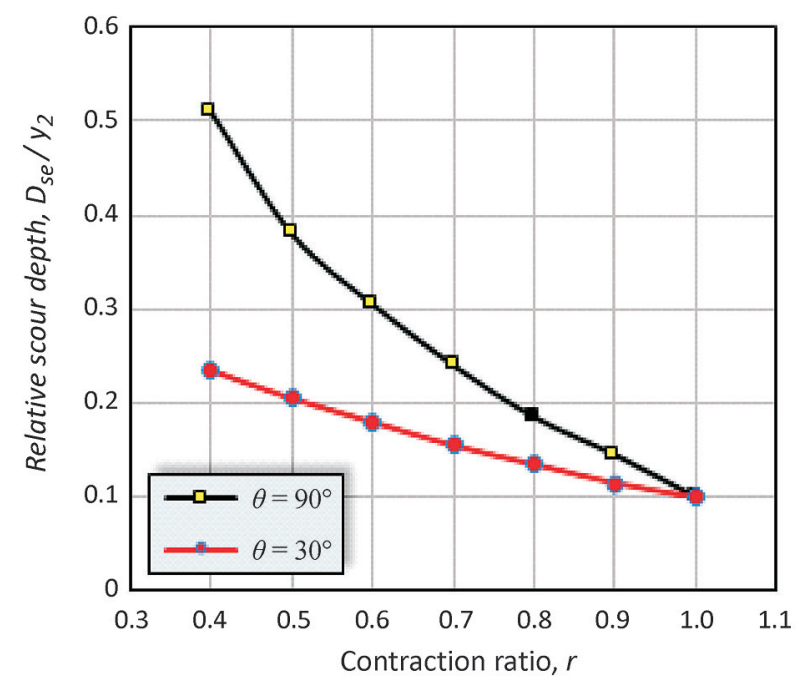

Fig. 13. Relation between the relative scour depth $\left(D_{s e} / y_{2}\right)$ and the relative contracted width ratio $(r)$

creasing the upstream Froude number, and at a constant upstream Froude number, the relative upstream energy loss increases by reducing the relative contracted width ratio.

Figure 13 shows the relation between the relative scour depth $\left(D_{s e} / y_{2}\right)$ and the relative contracted width ratio $(r)$, for the two used models of different transition angles, while Figure 14 shows the relation between the relative scour length $\left(L_{s e} / y_{2}\right)$ and the relative contracted width ratio $(r)$ for the same two models, from which it can be noticed that the scour depth and length at transition angle $\theta=90^{\circ}$ are higher than those at transition angle $\theta=30^{\circ}$ at the same value of the relative contracted width ratio. Using relative contracted width ratios 0.9 ,

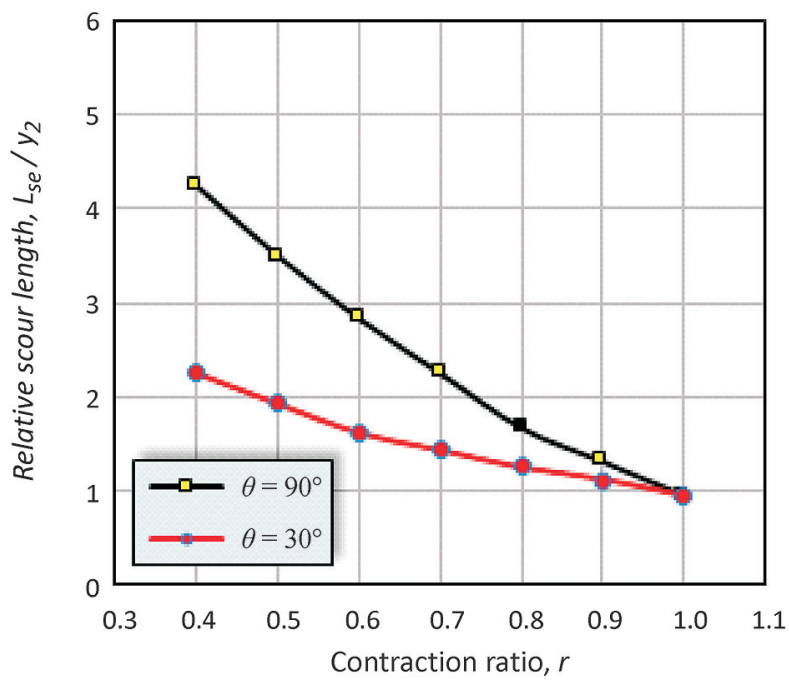

Fig. 14. Relation between the relative scour length $\left(L_{s e} / y_{2}\right)$ and the relative contracted width ratio $(r)$
Table 1. Effect of the relative contracted width ratio $(r)$ on the different hydraulic parameters. RMSE is the root mean square error

\begin{tabular}{|l|c|}
\hline \multicolumn{1}{|c|}{ Equation } & RMSE \\
\hline \multicolumn{1}{|c|}{ Transition angle $\theta=30^{\circ}$} \\
\hline$\left(h_{u} / y_{1}\right)=0.080+0.333\left(F_{1}\right)-0.128(r)$ & 0.037 \\
\hline$\left(y s / y_{1}\right)=0.879-0.522\left(F_{1}\right)+0.188(r)$ & 0.040 \\
\hline$\left(\Delta \mathrm{E}_{1} / y_{1}\right)=0.246+0.059\left(F_{1}\right)-0.041(r)-0.211\left(y s / y_{1}\right)$ & 0.006 \\
\hline \multicolumn{2}{|c|}{ Transition angle $\theta=90^{\circ}$} \\
\hline$\left(h_{u} / y_{1}\right)=0.104+0.347\left(F_{1}\right)-0.159(r)$ & 0.049 \\
\hline$\left(y s / y_{1}\right)=0.865-0.560\left(F_{1}\right)+0.201(r)$ & 0.035 \\
\hline$\left(\Delta E_{1} / y_{1}\right)=0.348+0.049\left(F_{1}\right)-0.047(r)-0.306\left(y s / y_{1}\right)$ & 0.009 \\
\hline
\end{tabular}

$0.8,0.7,0.6,0.5$, and 0.4 increases the scour depth by about $45,85,140,205,280$, and $410 \%$, respectively, and increases the scour length by about $38,75,137,198$, 268 , and $347 \%$, for the model of transition angle $\theta=$ $90^{\circ}$, compared to the case of no contraction $(r=1)$. For the model of transition angle $\theta=30^{\circ}$, using relative contracted width ratios $0.9,0.8,0.7,0.6,0.5$, and 0.4 increases the scour depth by about $15,35,55,80,105$, and $135 \%$, respectively, and increases the scour length by about $18,32,51,70,103$, and $137 \%$ compared to the case of no contraction $(r=1)$. Due to the fact that decreasing the relative contracted width decreases the water area in the contracted zone which causes an increase in the velocity, the scour depth and length increase.

All the previous experimental runs for both models (model of $\theta=30^{\circ}$ and model of $\theta=90^{\circ}$ ) were repeated for another five values of discharge equal to $18.8,22.7$, $25.8,28.8$, and $30.9 \mathrm{dm}^{3} \mathrm{~s}^{-1}$ to introduce accurate equations for the effect of the relative contracted width ratio on the different hydraulic parameters by using the MATLAB program (Table 1). These equations may be used for Froude number $\left(F_{1}\right)$ ranging from 0.025 to 0.33 , the relative contracted width ratio $(r)$ varying between 0.4 and 1.0, and transition angle $\theta=30^{\circ}$. Similar relations were introduced for model of transition angle $\theta=90^{\circ}$ (Table 1$)$.

\section{Conclusions}

Through the experimental results and discussion, the following main points can be concluded:

1. The $30^{\circ}$ transition angle is the optimum angle from the hydraulic point of view and according to the cost of the wing wall.

2. For the used sand of a medium diameter $\left(D_{50}\right)=0.42$ $\mathrm{mm}$, the scour depth reaches about $90 \%$ of its maximum value after the first 30 minutes and it reaches the equilibrium state after about six hours for the different values of the available discharge.

3. The relative heading up and both the scour depth and length increase by a higher rate at relative contracted width ratios less than 0.6 for the used tran- 
sition angles. Accordingly, the better recommended relative contracted width ratio should not be less than 0.6 .

4. Using transition angle $\theta=30^{\circ}$, decreases the scour depth by about $41 \%$, and decreases the scour length by about $43 \%$ compared with the values obtained by using the $90^{\circ}$ transition angle for the concluded relative contracted width ratio $r=0.6$.

5. Statistical equations were introduced to analyse the effect of the relative contracted width ratio on the different hydraulic parameters.

\section{References}

Alsamman O.M., 1989, Flow characteristics in channel with local contractions [Thesis], King Saud University, Faculty of Engineering, Riyadh, $98 \mathrm{pp}$.

Attia M.I., 2000, Effect of contraction ratio and transition angle on the energy loss in horizontal open channel transitions, Proc. of the 5th International Water technology Conference (IWTC), 3-5 March 2000, Alexandria: 97106.

Attia M.I., Alhomidan A., 2013, Effect of free surface and Froude number on the protection length and turbulence in the compound transitions through bridges, Int. J. Res. Eng. Technol. (IJRET) 2(11): 394-411.

Devadason B.P.I., 2007, Contraction scour in compound channels with cohesive soil beds [Thesis], Texas A\&M University, College Station, 118 pp.
Dey S., Raikar V., 2005, Scour in long contractions, J. Hydraul. Eng. 131(12): 1036-1049.

Henderson F.M., 1966, Open channel flow, Macmillan. New York, $522 \mathrm{pp}$.

Ippen A.T., Dawson J.H., 1951, Design of channel contraction, T. Am. Soc. Civ. Eng. 116: 326-346.

Mohamed Y.A., Abdel-Aal G.M., Nasr-Allah T.H., Shawky A.A., 2016, Experimental and theoretical investigations of scour at bridge abutment, J. King Saud Univ. Eng. Sci. 28: $32-40$.

Negm A.M., Elfiky M.M., Attia M.I., Ezzeldin M.M., 2003, Protection length downstream of sudden transition for incoming sub critical flow, Proc. of the 1st International Conference of Civil Engineering Science (ICCES1) Vol. 1, October 2003, Assiut, 9 pp.

Wu B., Molinas A., 2005, Energy losses and threshold conditions for choking in channel contractions, J. Hydraul. Res. 43(2) 139-148.

Xiong X., Melville B.W., Friedrich H., 2013, Effects of contraction length on abutment scour, Proc. of the 35th IAHR Congress, 8-13 September 2013, Chengdu, $10 \mathrm{pp}$.

Zidan A.R., Owais T.M., Rashwan I.M., 1990, Horizontal transitions in subcritical flow, Mansoura Eng. J. (MEJ) 15(1): 221-242.

Zidan A.R., El-Gamal M.A., Abdallah M.G., Mohamed M.H., 2015, Compound transitions in open channels [Thesis], Mansoura University, Faculty of Engineering, Mansoura. 